\title{
STUDY OF THE CLINICAL PROFILE OF BLUNT ABDOMINAL TRAUMA AT A TERTIARY CARE CENTRE OF CENTRAL INDIA
}

\author{
Rishikant Vashistha1 ${ }^{1}$ Himanshu Bansal ${ }^{2}$, Sanjay Datey³, Neelam Charles ${ }^{4}$, Ashwin Lazarus ${ }^{5}$, Mohan Gadodia $^{6}$
}

${ }^{1}$ Assistant Professor, Department of General Surgery, Sri Aurobindo Medical College and Post Graduate Institute, Indore, M. P.

${ }^{2}$ Senior Resident, Department of General Surgery, Sri Aurobindo Medical College and Post Graduate Institute, Indore, M. P.

${ }^{3}$ Professor, Department of General Surgery, Sri Aurobindo Medical College and Post Graduate Institute, Indore, M. P.

${ }^{4}$ Professor, Department of General Surgery, Sri Aurobindo Medical College and Post Graduate Institute, Indore, M. P.

${ }_{5} 2^{\text {nd }}$ Year Surgery Resident, Department of General Surgery, Sri Aurobindo Medical College and Post Graduate Institute, Indore, M. P.

${ }^{6} 2^{\text {nd }}$ Year Surgery Resident, Department of General Surgery, Sri Aurobindo Medical College and Post Graduate Institute, Indore, M. P.

ABSTRACT: This observational study was conducted on the victims of blunt abdominal trauma from $1^{\text {st }}$ January 2012 to $31^{\text {st }}$ October 2013 at Sri Aurobindo Medical College and Postgraduate Institute, Indore, which is a leading tertiary care centre in Central India. Fifty three patients of blunt abdominal trauma were included in the study and analysed on the basis of clinical profile, demographic pattern and overall outcome of the injuries. Road traffic accident was the commonest cause (74.47\%). Sex distribution ratio showed male preponderance (81.13\%). More than half (55\%) were from the middle age group (20 to 40 years). These men must have been the sole breadwinners of their families and we can only imagine the socio-economical impact on their families. Most of them were involved in automobile accidents which could have been prevented. Increased use of fast moving vehicles and lack of knowledge about traffic regulations are responsible for these accidents. In the coming days the problem of polytrauma is going to increase in our hospitals. We should try to prevent the menace of automobile accidents. Rules and regulations of road safety and precautions while using the automobiles have to be imbibed at an earlier age. Schools, social media and licensing authorities of the government will have to play an important role in this matter. In spite of latest gadgets and state of art medical care facility, the outcome of abdominal trauma is marked by significant morbidity and mortality as it depends on concomitant injuries and unique problem of postoperative abdominal sepsis. We feel that proper understanding of etiology and pattern of blunt abdominal trauma may help in improving the final outcome.

KEYWORDS: Road Traffic Accidents, Blunt Splenic Tauma, Blunt Liver Trauma.

HOW TO CITE THIS ARTICLE: Rishikant Vashistha, Himanshu Bansal, Sanjay Datey, Neelam Charles, Ashwin Lazarus, Mohan Gadodia. "Study of the Clinical Profile of Blunt Abdominal Trauma at a Tertiary Care Centre of Central India". Journal of Evolution of Medical and Dental Sciences 2015; Vol. 4, Issue 93, November 19; Page: 15839-15842, DOI: 10.14260/jemds/2015/2296.

INTRODUCTION: Blunt abdominal trauma continues to be the major cause of morbidity and mortality, in spite of newer advancements in imaging leading to early recognition and prompt surgical management of internal abdominal injuries. Generally people of most active and productive age group are involved in blunt abdominal trauma which adds to a serious economic loss to the community. The most common cause of blunt polytrauma is automobile accidents. Abdomen being the important part of torso (Abdomen and thorax) is vulnerable to injury in any type of accident. Victims of blunt trauma can be difficult to diagnose as it can be associated with various other injuries which divert the attention of clinician. Symptoms and signs can appear very late in some cases delaying the diagnosis of blunt abdominal trauma.

Delay in diagnosis can be dangerous to the patient and can affect the overall morbidity and mortality. This observational study was conducted at Sri Aurobindo Medical College and Postgraduate Institute, Indore, which is a leading tertiary care centre of Central India. We feel that proper understanding of etiology and pattern of blunt abdominal trauma can help in improving the final outcome.

Financial or Other, Competing Interest: None.

Submission 01-10-2015, Peer Review 03-10-2015,

Acceptance 09-11-2015, Published 17-11-2015.

Corresponding Author:

Dr. Sanjay Datey,

43, Chikitsak Nagar,

Indore-452010, Madhya Pradesh.

E-mail: datesanjai@rediffmail.com

DOI:10.14260/jemds/2015/2296.
METHODOLOGY: This observational study on Blunt

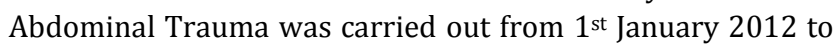
31 $1^{\text {st }}$ October 2013 at Sri Aurobindo Medical College and Postgraduate Institute of Indore. The work was started after approval from the institutional research and ethical committee. All patients of blunt abdominal trauma were included. Patients who left the hospital against medical advice were excluded from this study. Detailed history, findings of thorough clinical examination, relevent investigations, various treatment procedures and the outcome was recorded on the proforma on a periodical basis. Patient was followed and the progress was recorded till his/her discharge from hospital or death. All the data was entered on a master chart for the final tabulation. Analysis of the data was done by simple descriptive statistical methods with the help of biostatician. The study was concluded by comparison of observations with other available data which was gathered by review of the literature.

OBSERVATIONS: A total of fifty three patients $(n=53)$ of blunt abdominal trauma were studied. The observations are as follows:

In our study, as depicted in (Table - 1) the mean age of the victims of blunt abdominal trauma was found to be 25 years. Eighteen patients (33.96\%) were from the age group of 21-30. Half of the patients $(54.71 \%)$ were from $2^{\text {nd }}$ and $3^{\text {rd }}$ decades of life. This further proves that young people are more vulnerable to blunt abdominal trauma than any other age group. 


\begin{tabular}{|c|c|c|}
\hline Age (In years) & $\begin{array}{c}\text { Number of } \\
\text { Patients }\end{array}$ & Percentage (\%) \\
\hline $1-10$ & 10 & 18.86 \\
\hline $11-20$ & 11 & 20.75 \\
\hline $21-30$ & 18 & 33.96 \\
\hline $31-40$ & 7 & 13.20 \\
\hline $41-50$ & 3 & 5.66 \\
\hline \multicolumn{3}{|c|}{$\begin{array}{r}\text { Table 1: Age wise Distribution of } \\
\text { Patients and Percentages }\end{array}$} \\
\hline
\end{tabular}

\begin{tabular}{|c|c|c|}
\hline Sex & Number of Patients & Percentage \\
\hline Male & 43 & 81.13 \\
\hline Female & 10 & 18.86 \\
\hline \multicolumn{2}{|c|}{ Table 2: Sex Distribution of Patients and Percentage } \\
\hline
\end{tabular}

(Table - 2) clearly shows the male preponderance in the sex distribution of victims. Forty three $(81.13 \%)$ were males out of 53 victims of blunt abdominal trauma.

\begin{tabular}{|c|c|c|}
\hline Mode of Trauma & Number of Patients & Percentage \\
\hline Road traffic accidents & 40 & $75.47 \%$ \\
\hline Fall from height & 5 & $9.43 \%$ \\
\hline Assault & 4 & $7.54 \%$ \\
\hline Fall of object/wall & 4 & $7.54 \%$ \\
\hline \multicolumn{2}{|c|}{ Table 3: Mode of Injuries of Patients } \\
\hline
\end{tabular}

The commonest mode of the injury was found to be Road Traffic Accidents (75.47\%). Other reasons for blunt abdominal trauma included fall from height (5), assault (4) and fall of wall (4). Out of total 53 patients studied in our series.

\begin{tabular}{|c|c|}
\hline Associated Injuries & Number of Patients \\
\hline Head injury & 3 \\
\hline Fracture of spine & 1 \\
\hline Fracture of pelvis & 5 \\
\hline $\begin{array}{c}\text { Fracture of ribcage with } \\
\text { pulmonary complications }\end{array}$ & 4 \\
\hline \multicolumn{2}{|c|}{ Table 4: Associated Injuries } \\
\hline
\end{tabular}

Out of the fifty three patients studied, sixteen patients had associated injuries which comprised of head, spine, chest, pelvis and long bone injuries. The chart (Table - 4) shows number of various other injuries which were associated with blunt abdominal trauma.

\begin{tabular}{|c|c|}
\hline Duodenum & 2 \\
\hline Jejunum & 12 \\
\hline Ileum & 5 \\
\hline Liver & 18 \\
\hline Spleen & 9 \\
\hline Stomach & 6 \\
\hline Kidney & 3 \\
\hline Urinary bladder & 3 \\
\hline Colon & 2 \\
\hline Retroperitoneum & 2 \\
\hline Pancreas & 1 \\
\hline Diaphragm & 1 \\
\hline \multicolumn{2}{|c|}{ Table 5: Pattern of Visceral Involvement } \\
\hline
\end{tabular}

Table - 5 shows the pattern of visceral involvement of various intra-abdominal organs. According to our data small bowel (19), liver (18) and spleen (9) were the commonest organs which suffered injury in case of blunt abdominal trauma. Out of 53 patients, 22 patients were managed conservatively and 31 were operated.

\begin{tabular}{|c|c|}
\hline Total number of liver trauma & 18 \\
\hline Conservatively managed & 11 \\
\hline Operative management & 5 \\
\hline Deaths & 2 \\
\hline Table 6: Management of Blunt Liver Trauma \\
\hline
\end{tabular}

Several patients of blunt abdominal trauma have hemoperitoneum due to solid organ (Liver and spleen) injuries. With the advent of sophisticated imaging modalities, the exact nature and extent of injury to liver and spleen can be diagnosed. In our series of 53 patients, 11 patients of liver trauma were managed conservatively and discharged.

\begin{tabular}{|c|c|}
\hline Total number of blunt splenic trauma & 9 \\
\hline Conservatively managed & 3 \\
\hline Operative treatment & 5 \\
\hline Death & 1 \\
\hline Table 7: Management of Blunt Splenic Trauma \\
\hline
\end{tabular}

Out of the nine patients of isolated splenic trauma 3 were managed conservatively and five received treatment, one patient succumbed to the injury.

\begin{tabular}{|c|c|c|}
\hline Clinical Features & $\begin{array}{c}\text { Total Number of } \\
\text { Patients }\end{array}$ & $\begin{array}{c}\text { Percentages } \\
(\%)\end{array}$ \\
\hline Pain & 49 & 92.45 \\
\hline Vomiting & 20 & 37.73 \\
\hline Distension & 30 & 56.60 \\
\hline Guarding & 31 & 58.49 \\
\hline Rigidity & 28 & 52.83 \\
\hline Tenderness & 51 & 96.22 \\
\hline $\begin{array}{l}\text { Absent bowel } \\
\text { sounds }\end{array}$ & 24 & 45.28 \\
\hline Hypotension & 9 & 16.98 \\
\hline
\end{tabular}

Table 8 shows the incidence of various clinical features in the patients studied. Out of fifty three, pain (92.45\%) and tenderness (96.22\%) over abdomen were the commonest features. Other features were guarding (58.49\%), distension $(56.60 \%)$, rigidity $(52.83 \%)$, absence of bowel sounds (45.28\%) and vomiting (37.73\%). Only nine (16.98\%) patients presented with hypotension.

\begin{tabular}{|c|c|c|}
\hline Days & Number of Patients & Percentage (\%) \\
\hline $1-10$ & 24 & 45.28 \\
\hline $11-20$ & 17 & 32.07 \\
\hline $21-30$ & 6 & 11.32 \\
\hline $31-40$ & 4 & 7.54 \\
\hline $41-50$ & 1 & 1.88 \\
\hline 51 -above & 1 & 1.88 \\
\hline \multicolumn{3}{|c|}{ Table 9: Duration of Hospital Stay } \\
\hline
\end{tabular}

Above chart (Table - 9) depicts the number of days, a patient of blunt abdominal trauma stayed in the hospital. Average stay was 13.92 days. Hospital stay directly indicates the magnitude of trauma a patient has suffered. It is observed that hospital stay increases with complications either related to associated injuries or postoperative sequelae. 


\begin{tabular}{|c|c|c|}
\hline Category & $\begin{array}{c}\text { Number of } \\
\text { Patients }\end{array}$ & $\begin{array}{c}\text { Percentage } \\
(\%)\end{array}$ \\
\hline $\begin{array}{c}\text { Discharged after } \\
\text { conservative treatment }\end{array}$ & 21 & 39.62 \\
\hline $\begin{array}{l}\text { Discharged after operative } \\
\text { treatment }\end{array}$ & 23 & 43.39 \\
\hline Death due to injury & 9 & 16.98 \\
\hline
\end{tabular}

Nine patients (16.98\%) of blunt abdominal trauma could not be saved in spite of all efforts. Out of the remaining 44 patients, twenty one (39.62\%) were managed conservatively and discharged in a satisfactory condition.

DISCUSSION: Rapid economic growth and urbanization with changing life styles has led to increasing use of high speed automobiles. Polytrauma is increasing because of vehicular accidents and resulting in avoidable morbidity and mortality in young population. The present observational study was conducted with an aim to study the demographic pattern, various modes and outcome of blunt abdominal trauma in our locality.

In this study, it has been seen that the patients (33.96\%) between 21-30 years were most commonly suffered from blunt abdominal trauma. More than half $(54.71 \%)$ patients were from $2^{\text {nd }}$ and $3^{\text {rd }}$ decades of life. S. Gupta et al.(1) in their study of 63 patients had 875 below the age of 40 years. Deodhar SD et al.(2) in a study of 51 patients of blunt and penetrating trauma also found that patient in $2^{\text {nd }}$ and $3^{\text {rd }}$ decades are common victims. The highest incidence in this age group can be attributed to the active lifestyle of this age group with highest exposure to external environment, use of automobiles, working with machinery, assaults and contact sports.

Male preponderance was noted with incidence of (81.13\%). Similar findings have been noted by S. Gupta.(1) Deodhar.(2) M. Mukhopadhyay.(3) and Davis JJ et al.(4) The relatively low incidence in females (10 out of 53) can be explained on the basis that females are less exposed to external environmental factors.

Motor vehicle accidents accounted for more than three fourth $(75.47 \%)$ of blunt abdominal trauma followed by falls $(09.43 \%)$, assault $(07.54 \%)$ and fall of object/wall $(07.54 \%)$. S. Gupta et al. reported $50 \%$ patients due to vehicular accidents. Several other studies have reported similar incidence. $(5,6,7)$ Isolated blunt abdominal trauma is due to direct blows and compression injuries in vehicular accidents. We came across higher number of patients with polytrauma, in which abdominal viscera is also injured. Automobile accidents are the causes of these injuries, where a person is either trapped between the parts of a collided vehicle or is run over by the vehicle. In many cases victim is ejected on the road from a fast moving vehicle. All the three mechanisms described in causation of blunt abdominal trauma i.e. deceleration injury, crush injury or compression injury can come into play.

These victims can have many other injuries e.g.-head injury, spine injury, pelvis, chest, long bone fractures. In our study we found that fracture of long bones, rib cage fractures and pelvic fractures were commonest associated injuries.

Single or multiple intraabdominal organs can be traumatized due to blunt trauma. Normally magnitude and location of trauma decides the regional organ involvement, but the small intestine and parts of colon are exceptions to this rule. Injuries to these parts can be variable and depends on their contents. Fluid or gas filled small intestine, sigmoid colon loaded with faeces have different momentums at the time of impact. This leads to mesenteric tears or bursting of the lumen.

In our study, small intestine was the commonest viscera (19 out of 53 ) to be injured. The second commonest was liver (18 out of 53). Spleen ( 9 out of 53) was found to be third in the order of frequency in our study contrary to many other studies in which spleen was found to be the most commonly injured organ. Liver injury was common than spleen in the study of 63 patients by S. Gupta et al.(1) Deodhar et al.(2) also have reported a greater incidence of liver injuries as compared to spleen. S. Gupta et al. and Deodhar et al. have noted similar findings of pain and tenderness as the commonest presenting features. As we all know clinical features may appear late in the course of an illness and initially an young individual with blunt abdominal trauma can be absolutely stable with normal parameters and trivial pain. Repeated clinical examination and close monitoring is of utmost importance. Delay in diagnosis of an intra-abdominal injury can be disastrous as it will delay operative treatment thereby increasing the morbidity and mortality.

In our study of 53 patients, we had a mortality of $16.98 \%$. Out of the 53 patients 44 were discharged in a satisfactory condition. Twenty three (43.39\%) undergone surgical treatment, while the remaining 21 patients were managed conservatively. Death of nine patients $(16.78 \%)$ is comparable to the figures given by S. Gupta et al. (11.11\%) and Deodhar et al. (20\%). Outcome of victims of blunt abdominal trauma depends on various factors. Morbidity and mortality varies with age, body habitus, force and location of trauma. It also depends on comorbidities and magnitude of associated injuries. Delay in diagnosis and treatment, sepsis and respiratory complications increase the mortality.

CONCLUSION: Early diagnosis and prompt surgical treatment will help in reducing the morbidity and mortality associated with blunt abdominal trauma. Effect of associated injuries, abdominal sepsis and respiratory complications are the major detractors in the recovery of a patient with blunt abdominal trauma. As we have seen from our review of literature maximum number of victims are young males involved in automobile accidents. Social awareness regarding traffic safety seems to be a solution to this problem. Otherwise in the coming days we are going to see more and more of polytrauma and blunt abdominal trauma.

\section{REFERENCES:}

1. S. Gupta, S. Talwar, RK Sharma et al; Blunt trauma abdomen: A study of 63 cases. Indian Jr. of Med Science: 1996; Aug 50(8) 272.

2. Deodhar SD, Patel NP, Shah KB, Jammihal HJ; Blunt and penetrating injuries (A study of 51 cases), j Postgraduate Med. 1983; 29:96.

3. Mukhopadhyay $\mathrm{M}$ : Intestinal injury from blunt abdominal trauma: A study of 47 cases. OMJ 24, 256259 (2009).

4. Davis JJ, Cohn Jr, NanceFC: diagnosis and management of Blunt abdominal trauma. Ann Surg. June 1976; 183(6): 672. 
5. Dauterive AH, Flancbaum L, Cox EF: Blunt intestinal trauma. A Modern day review. Ann Surg. 1985; 201,198203.
6. Allen GS, Moore FA, Cox CS et al: Hollow visceral injury and blunt trauma. Jr. Trauma:1998; 45; 69-78.

7. Wisner DH, Y. Chun, W. Blaisdell: Blunt intestinal injury, Arch Surg. Vol.125, Oct 1990.1319-1323. 